\title{
Mbarara University Research Training Initiative: a spin-off of the Medical Education Partnership Initiative in Uganda
}

This article was published in the following Dove Press journal:

Advances in Medical Education and Practice

27 July 2017

Number of times this article has been viewed

\author{
Edith Wakida' \\ Samuel Maling ${ }^{2}$ \\ Celestino Obua ${ }^{3}$ \\ 'Office of Research Administration, \\ 2Department of Psychiatry, Office \\ of the Dean, Faculty of Medicine, \\ ${ }^{3}$ Department of Pharmacomology \\ and Therapeutics, Office of the Vice \\ Chancellor, Mbarara University of \\ Science and Technology, Mbarara, \\ Uganda
}

Correspondence: Edith Wakida Office of Research Administration, Mbarara University of Science and Technology, PO Box 1410, Mbarara, Uganda

Tel +256 78268554 I

Email ediwakida@must.ac.ug
Abstract: Scientific productivity in Africa is insignificant compared to that in the rest of the world. This has been attributed to the fact that, in spite of academic qualifications, junior faculty, who form the majority of academics in low- and middle-income countries lack experience in research. This calls for a need to put in place programs that provide hands-on training in research so that junior faculty can conduct relevant research. The Mbarara University Research Training Initiative, a Fogarty International Center-funded program, is one such program that was developed to provide research capacity training for junior faculty at the Mbarara University of Science and Technology. The program utilizes health priority areas to provide research training to junior faculty. During the training, they are given short-term-focused research training on particular knowledge and skills, which they apply while conducting the mentored research.

Keywords: junior faculty, MURTI, short training, mentored research

\section{Background}

Scientific productivity in Africa is insignificant compared to that in the rest of the world. ${ }^{1}$ This is attributed to the fact that, in spite of academic qualifications, junior faculty, who form the majority of academics in low- and middle-income countries (LMICs) lack experience in research. This calls for a need to put in place training programs that provide hands-on practice in research to build their capacity to become independent researchers. ${ }^{2}$ A systematic review that investigated the approaches and impact of nonacademic research capacity-strengthening training models in sub-Saharan Africa (SSA) found that research capacity-strengthening training programs fell into two broad categories: longer training programs that covered multiple competencies, and shorter programs that covered single research competencies. It was further found that the shorter programs did not have practical projects nor did they provide mentorship programs to trainees. ${ }^{1}$

The Mbarara University of Science and Technology (MUST) was established to train health care providers and scientists to improve health and advance development in rural Uganda. MUST participated in the Medical Education Partnership Initiative (MEPI) program through the Medical Education for Equitable Services to All Ugandans (MESAU) consortium. While scientific, administrative, and infrastructure capacity was developed during the MEPI-MESAU program, the primary focus for MEPI was medical education for students. The program did not address research capacity for junior faculty. 
As a result, MUST - in partnership with Massachusetts General Hospital (MGH) and Harvard School of Public Health (HSPH) - responded to the call for Research Training for Career Development of Junior Faculty in MEPI institutions. The MUST program in response to this call was named Mbarara University Research Training Initiative (MURTI), which obtained funding under grant number D43TW010128. In the establishment of the MURTI program, two program oversight committees (Program Implementation Committee [PIC] and the Training Advisory Committee [TAC]) were constituted. The PIC comprises the two program directors, five program faculty members, and the Academic Registrar, whose role involves the technical implementation of the program. The TAC comprises two US and five Ugandan members, who provide oversight to the program and select junior faculty for fellowship.

\section{Aim}

The overall aim of the MURTI program is building capacity of junior faculty so that its members become the next generation of researchers in Africa, who will conduct locally relevant research that contributes to improved health with the following specific aims: 1) developing research expertise of junior faculty in HIV prevention and treatment, particularly in rural southwestern Uganda; 2) building the capacity of Ugandan junior faculty to develop novel, evidence-based diagnostic and treatment strategies for cardiovascular diseases (CVDs) in rural populations to address priority health needs in this area; 3 ) preparing junior faculty for research careers addressing mental health disorders in rural Uganda; and 4) equipping junior faculty with the administrative ability, research ethics, and research communication capacities necessary to succeed as the next generation of independent investigators in Uganda.

\section{Methods}

In training of the junior faculty, MURTI chose a model that utilizes shorter training programs while covering multiple competencies over the duration of the fellowship. ${ }^{1}$ Utilizing this approach, mentorship is provided to the mentee from the beginning to the end of the fellowship. During the fellowship, they are given short-term focused research training on particular knowledge and skills. They are also paired to mentors (local and international) so that they can benefit from the different experiences of the mentors. Furthermore, the mentees are provided with seed grants to conduct mentored research, at the end of which they should publish their research findings. The Fellows' progress is monitored using an individual development plan (IDP) that each Fellow devel- ops with her/his mentor(s). The IDP is based on identifying four principles: strengths on which to build, weaknesses to improve, opportunities to exploit, and threats to mitigate. It outlines at least four activities to be undertaken to address each principle, the timelines, support needed, and expected output. Performance is reported to the PIC quarterly and to the TAC annually.

To structure and provide the most feasible and relevant training, the MURTI draws on the extensive experience of the faculty mentors to meet the training needs of junior faculty in specific aspects of priority infectious disease (HIV/ AIDS) and noncommunicable diseases (NCDs) (neurological diseases, CVDs and mental health disorders (Figure 1). HIV/ AIDS and NCDs, including mental health disorders, are the leading causes of morbidity and mortality in SSA. ${ }^{3}$ These areas are highly related and interdependent; for instance, HIV contributes to mental disorders, including depression and impaired executive function, as well as CVDs, through inflammation-mediated endothelial damage. ${ }^{4-8}$ Mental disorders, particularly depression and impaired executive function, negatively affect every step in the "cascade of care". CVDs make an increased contribution to disease burden as HIV morbidity and mortality decline. ${ }^{9-14}$ In Uganda, gaps still exist in addressing research in these diseases of public health concern. ${ }^{15}$

\section{Approaches to addressing the priority areas \\ HIV}

While the HIV research infrastructure is relatively well developed in Uganda, important gaps remain in some specific areas, such as Good Clinical Laboratory Practice (GCLP) and fundamentals of molecular diagnostics related to HIV and other diseases. ${ }^{16,17}$

\section{Mental health}

This is a priority area within the NCDs in the country, ${ }^{18}$ and therefore the need to conduct more research on the burden for mental health disorders in Uganda is imperative. ${ }^{19}$ MUST investigators have conducted some studies on mental health, and these have largely been by international investigators, ${ }^{20,21}$ with minimal involvement of local investigators, the majority of whom are junior faculty. It is therefore important to focus on the capacity of junior faculty to conduct research in mental health. In addition, mental health research in children and adolescents is an area that requires special focus in Uganda. ${ }^{22}$ It has been reported that while neuropsychiatric illness in childhood and adolescence represents $15-30 \%$ of all loss in 


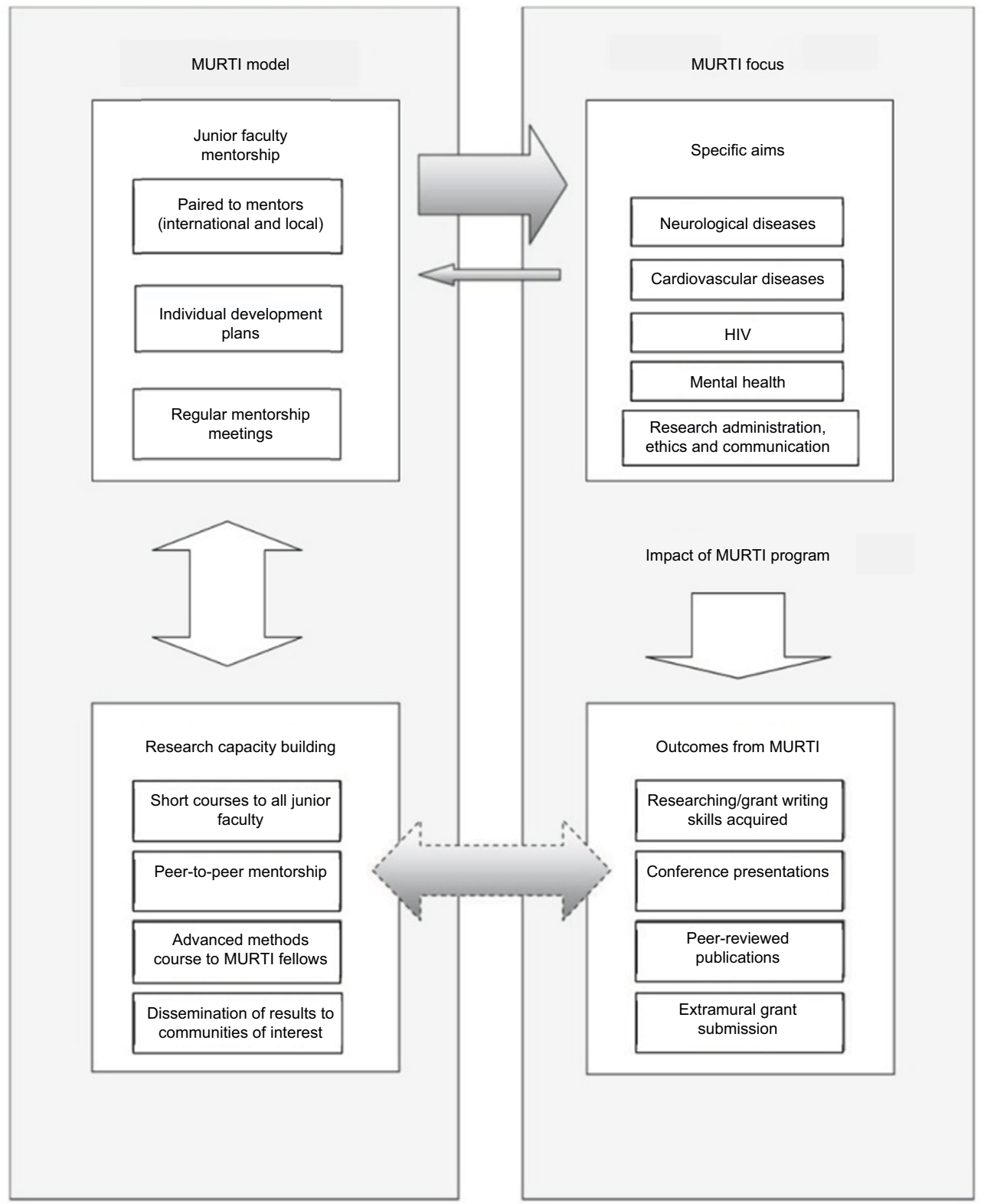

Figure I Structural analysis of the MURTI program.

Notes: The figure shows the main components of the MURTI program. On the left side is the MURTI model, while on the right is the scientific (research) focus of the program. The bold arrow shows that the model feeds into the research focus; the smaller arrow indicates feedback into the model. The dotted arrow indicates the interaction between the scientific focus outcome and the research capacity-building efforts.

Abbreviation: MURTI, Mbarara University Research Training Initiative.

disability-adjusted life years, service systems in LMICs such as Uganda are weak. ${ }^{23}$ The weakness in the service system could possibly be due to insufficient research addressing mental illnesses in these age groups.

\section{Neurological disorders}

Studies conducted in Uganda show that neurological Disorders (NDs), in particular cerebrovascular disease (stroke), are common, understudied, and underdiagnosed. ${ }^{24}$ The MURTI training in NDs focuses on one of the following areas: neurology in HIV, including stroke; risk and prevention for cerebrovascular disorders; and neuroradiology.

\section{Research administration, ethics, and communication}

The Office of Research Administration (ORA) in the Faculty of Medicine at MUST was set up with MEPI-MESAU support to build capacity, support the faculty in submitting research grant applications, and conduct the ensuing research. The ORA is at the forefront of mentorship activities to support the conduct of research. With MEPI support, a 
mentorship guide was adapted from the Mentors' Manual for Health Sciences Training in Africa. ${ }^{25}$ Peer-to-peer mentorship is promoted for faculty, researchers, research administrators, and students. To manage the scope of work and training at the faculty level, ORA works with the central MUST Grants Office (MGO), which manages the research finances for all sponsored research activities at the university. ORA supports the MURTI program in administrative areas, such as managing the mentor-mentee contracts, including follow-up of progress and performance and preparation of mentorship reports.

In order to continuously advance the MEPI-MESAU aim of establishing functional critical support systems to nurture and sustain high-quality locally driven transdisciplinary research to promote health in Uganda, the ORA identified the need to train junior faculty in grants administration and other related research career development courses, as well as strengthen research administration at MUST. The overarching need of the office is to equip junior faculty with both administrative and research capacity to be able to conduct relevant research that contributes to improved human health and to foster faculty researchers.

The ORA identified and engaged experienced facilitators to develop and administer research capacity development courses to junior faculty in 2015-2016. The courses conducted included the following: Responsible Conduct of Research; Grant Writing, Administration, and Management; Scientific Manuscript Writing; Intellectual Property; Data Management, Systematic Review of Research Literature, Endnote Reference Manager, Qualitative Research Methods, Implementation Research, Archiving and Retrieving of Research Samples, Quantitative Research Methods, Developing Policy Briefs, Fundamentals of Molecular Diagnostics, Good Clinical Laboratory Practice, Development of Psychological Tools, and Advanced Research Methods.

\section{Results}

In terms of the progress on the program-specific aims, the first four Fellows were selected in the following areas.

\section{Aim I: to develop junior faculty research expertise in HIV prevention and treatment, particularly in rural southwestern Uganda}

One Fellow, a physician and clinical microbiologist whose research interests are HIV-associated opportunist infections, particularly cryptococcal meningitis and tuberculosis, was selected. He is working on two related seed grant projects with two international and two local mentors. He is examining the "Relation of fungal strain genotype to neurological complications in patients with HIV-associated cryptococcal meningitis: A retrospective multisite study," with the aim to explore the influence of cryptococcal molecular type on the development of neurological complications in patients with cryptococcal meningitis using data collected during the Cryptococcal Optimal Antiretroviral Timing (COAT) trial. ${ }^{26}$ This will lead to his second project that aims to evaluate the trends of gene transcription following cryptococcal meningitis. This pilot study is aimed at optimizing methods for in vivo isolation and storage of messenger rRNA and using this to compare gene expression in cryptococcal meningitis patients with and without neurological complications in order to decipher the role of particular genes in disease severity, development of drug resistance, and immune response. The results will be used to identify drug targets, predict and modify treatments, and predict onset of drug resistance. Data will also be used to evaluate the role of personalized treatment in improving health outcomes. These data from the second project also will be used to explain findings from the first.

\section{Aim 2: to develop the capacity of Ugandan junior faculty to develop novel, evidence-based diagnostic and treatment strategies for CVDs in rural populations to address priority health needs}

We did not plan to recruit a CVD Fellow in Year 01.

\section{Aim 3: to prepare junior faculty for research careers addressing mental health disorders in rural Uganda}

One Fellow, a female physiatrist, was selected in this area. She is mentored by one local mentor from Makerere University as well as international mentors from MGH and Simon Fraser University (SFU), Canada. Her research focus is on the "Association between depression, stigma and discrimination, bullying and victimization, social support among children and adolescents infected and affected by HIV". As a result of this work, she presented two abstracts: one to the $21 \mathrm{st}$ International AIDS conference in Durban, South Africa, July 18-22, 2016, titled "Validity and reliability of the HSCL-25 among HIV positive adults in rural Uganda"; and the other to the MUST Reproductive Health Research Conference, 
May 26, 2016, titled "Understanding coping strategies during pregnancy and the postpartum period: a qualitative study of women living with HIV in rural Uganda".

\section{Aim 4: to develop the capacity of Ugandan junior faculty to develop novel, evidence-based diagnostic and treatment strategies for CVD and mental health, as well as for use of neuroradiology in rural populations, to address priority health needs in rural populations}

Two females were selected as Fellows under this aim. One is an ear, nose, and throat (ENT) surgeon with a research focus on "Sensory and neural hearing loss among HIVpositive children between 6 and 12 years at Mbarara Regional Referral Hospital". She has a local mentor from MUST and two international mentors from the University of British Columbia. She is using the PATH Sentiero equipment for advanced audiological tests to carry out otoacoustic emissions and auditory brainstem response (OAE and ABR, respectively) during data collection. The other Fellow is a pediatrician focusing on "Patterns of Cardiac Disease and their relationship to Neurocognitive Development Among Children Attending Mbarara Regional Referral Hospital." She is mentored by an international mentor from McGill University, Canada, and a local mentor from Uganda Heart Institute/Makerere University. She is using the Bailey's III kit and the ECG machine to assess development in children during data collection.

\section{Aim 5: to equip junior faculty with the administrative, research ethics, and research communication capacities necessary to succeed as the next generation of independent investigators in Uganda}

In addition to the focus on the four MURTI Fellows appointed each year (who are required to take all core courses, an advanced research methods course, and relevant elective courses), the program is committed to building the research capacity of junior faculty and research administrators at MUST.

Significant outcomes from the capacity-building activities are as follows: 44 junior faculty members were trained in Responsible Conduct of Research, 18 in Grant Writing, 22 in Scientific Manuscript Writing, 12 in Intellectual Property, 31 in Data Management, 17 in Systematic Literature Review, 28 in EndNote Reference Manager, 32 in Qualitative Research Methods, 19 in Archiving and Retrieving of Research Samples, 31 in Implementation Research, 26 in Fundamentals of Molecular Diagnostics, 63 in Good Clinical Laboratory Practice, 13 in Development of Psychological Tools, and 4 MURTI Trainees in Advanced Research Methods.

Out of the training, these Fellows were able to train other junior faculty within their departments on how to collect data for their seed projects; they provided peer mentorship, worked with postgraduate students in manuscript writing, and provided research supervision. As a result, two MURTI fellows were able to publish their work. ${ }^{27,28}$

Eight research teams were formed to conduct systematic reviews of literature on various project topics. The teams hope to register the protocols with the Cochrane database, the leading resource of systematic reviews in health care, and the PROSPERO registry.

After the grant writing training, eleven junior faculty members submitted concepts to the Makerere-Sida Bilateral Research Capacity Building program of the Swedish Government for funding to pursue Doctoral and Masters programs. One was given a postdoctoral fellowship and five secured $\mathrm{PhD}$ Scholarships at Makerere University, while six were given Masters Scholarships to study at MUST. Furthermore, the ORA developed a website (ora.must.ac.ug) to strengthen research communication at MUST.

\section{Discussion}

The model that has been chosen in this program is meant to maximize the scope of building capacity among the many junior faculty members at MUST while concentrating on the selected Fellows for specialized training in the scientific areas of focus. Using short training programs while covering multiple competencies has allowed the program to provide a wide range of knowledge and skills not only to the Fellows but to the wider community of junior faculty as was found important for capacity building in developing countries. ${ }^{1}$

The pairing of Fellows to international and local mentors created an opportunity to exploit the different experiences of the mentors while building useful networks; as a result, IDPs were developed and used as a tracking tool for their progress. The selected scientific areas were used as a training base to provide realistic training to address the existing gaps in the health priority areas. ${ }^{15}$

We have found that by choosing short training programs that cover multiple competencies, the model provides junior faculty with the necessary knowledge and skills to build their 
capacity to handle research relevant to our setting. The training facilitated the Fellows to provide peer mentorship to other junior faculty, form research teams, conduct research, and publish. This shows that the MURTI program can be effective in building capacity of junior faculty to conduct research.

\section{Conclusion}

It is possible to build capacity of junior faculty through training programs such as the MURTI.

\section{Acknowledgments}

The authors acknowledge support from many collaborators and partners who have assisted in making the MURTI program viable. We acknowledge the members of the Training Advisory Committee for the support and technical advice. We are particularly grateful to Drs David Bangsberg, Mark Siedner, Ryan Carroll, and Pat Daoust for their unwavering support to the MURTI program. We acknowledge Drs Brian Westerberg, Heather Southam, Francis Bajunirwe, Frances Aboud, Charles Mondo, David Boulware, Conrad Muzoora, Joel Bazira, Eugene Kinyanda, Christine Cooper-Vince, Lynn T Matthews, and Angela Kaida for their invaluable role as mentors on the program.

This publication was supported by the Fogarty International Center (National Institutes of Health [NIH] Common Fund, Office of Strategic Coordination, Office of the Director [OD/OSC/CF/NIH]; Office of AIDS Research, Office of the Director (OAR/NIH); National Institute of Mental Health [NIMH/NIH]; National Institute of Neurological Disorders and Stroke [NINDS/NIH]) of the NIH under award number D43 TW010128. The content is solely the responsibility of the authors and does not necessarily represent the official views of the NIH.

\section{Disclosure}

Edith Wakida is the Research Manager in the Office of Research Administration at Mbarara University of Science and Technology and the key person responsible for research administration, ethics, and communication on the MURTI program. Samuel Maling is an Associate Professor of Psychiatry, Dean of Faculty of Medicine at Mbarara University of Science and Technology, and the Program Director II in charge of the day-to-day activities of MURTI program. Celestino Obua is a Professor of Pharmacology, the Vice Chancellor of Mbarara University of Science and Technology, and the Contact Program Director for the MURTI program. The authors report no other conflicts of interest in this work.

\section{References}

1. Mugabo L, Rouleau D, Odhiambo J, et al. Approaches and impact of non-academic research capacity strengthening training models in subSaharan Africa: a systematic review. Health Res Policy Syst. 2015;13:30.

2. Käser M, Maure C, Halpaap BM, et al. Research capacity strengthening in low and middle income countries-an evaluation of the $\mathrm{WHO} /$ TDR career development fellowship programme. PLoS Negl Trop Dis. 2016;10(5):e0004631

3. Holmes MD, Dalal S, Volmink J, et al. Non-communicable diseases in sub-Saharan Africa: the case for cohort studies. PLoS Med. 2010;7(5):e1000244.

4. Bendavid E, Ford N, Mills EJ. HIV and Africa's elderly: the problems and possibilities. AIDS. 2012;26(suppl 1):S85-S91.

5. Bloomfield GS, Khazanie P, Morris A, et al. HIV and noncommunicable cardiovascular and pulmonary diseases in low- and middle-income countries in the ART era: what we know and best directions for future research. J Acquir Immune Defic Syndr. 1999;2014(67 suppl 1): S40-S53.

6. Gresele P, Falcinelli E, Momi S, Francisci D, Baldelli F. Highly active antiretroviral therapy-related mechanisms of endothelial and platelet function alterations. Rev Cardiovasc Med. 2014;15(suppl 1): S9-S20.

7. Narayan KM, Miotti PG, Anand NP, et al. HIV and noncommunicable disease comorbidities in the era of antiretroviral therapy: a vital agenda for research in low- and middle-income country settings. J Acquir Immune Defic Syndr. 1999;2014(67 suppl 1):S2-S7.

8. Triant VA. Epidemiology of coronary heart disease in patients with human immunodeficiency virus. Rev Cardiovasc Med. 2014;15(suppl 1):S1-S8

9. Almeida SM. Cognitive impairment and major depressive disorder in HIV infection and cerebrospinal fluid biomarkers. Arq Neuropsiquiatr. 2013;71(9B):689-692.

10. Arseniou S, Arvaniti A, Samakouri M. HIV infection and depression. Psychiatry Clin Neurosci. 2014;68(2):96-109.

11. Chibanda D, Benjamin L, Weiss HA, Abas M. Mental, neurological, and substance use disorders in people living with HIV/AIDS in low- and middle-income countries. J Acquir Immune Defic Syndr. 1999;2014(67 suppl 1):S54-S67.

12. Del Guerra FB, Fonseca JL, Figueiredo VM, Ziff EB, Konkiewitz EC. Human immunodeficiency virus-associated depression: contributions of immuno-inflammatory, monoaminergic, neurodegenerative, and neurotrophic pathways. J Neurovirol. 2013;19(4):314-327.

13. Mayston R, Kinyanda E, Chishinga N, Prince M, Patel V. Mental disorder and the outcome of HIV/AIDS in low-income and middle-income countries: a systematic review. AIDS. 2012;26(suppl 2):S117-S135.

14. Nakimuli-Mpungu E, Bass JK, Alexandre P, et al. Depression, alcohol use and adherence to antiretroviral therapy in sub-Saharan Africa: a systematic review. AIDS Behav. 2012;16(8):2101-2118.

15. Bajunirwe F, Tumwebaze F, Abongomera G, Akakimpa D, Kityo C, Mugyenyi PN. Identification of gaps for implementation science in the HIV prevention, care and treatment cascade; a qualitative study in 19 districts in Uganda. BMC Res Notes. 2016;9(1):217.

16. Shott JP, Galiwango RM, Reynolds SJ. A quality management approach to implementing point-of-care technologies for HIV diagnosis and monitoring in Sub-Saharan Africa. Re Dai Yi Xue Za Zhi. 2012;2012:651927.

17. Schito M, Peter TF, Cavanaugh S, et al. Opportunities and challenges for cost-efficient implementation of new point-of-care diagnostics for HIV and tuberculosis. J Infect Dis. 2012;205(suppl 2):S169-S180.

18. Government of Uganda Ministry of Health. Health Sector Strategic Plan III 2010/11-2014/15. Uganda: Government of Uganda Ministry of Health; 2010.

19. Kigozi F, Ssebunnya J, Kizza D, Cooper S, Ndyanabangi S; Mental Health and Poverty Project. An overview of Uganda's mental health care system: results from an assessment using the world health organization's assessment instrument for mental health systems (WHO-AIMS). Int $J$ Ment Health Syst. 2010;4(1):1. 
20. Tsai AC, Wolfe WR, Kumbakumba E, et al. Prospective study of the mental health consequences of sexual violence among women living with HIV in Rural Uganda. J Interpers Violence. 2016;31(8):1531-1553.

21. Hatcher AM, Tsai AC, Kumbakumba E, et al. Sexual relationship power and depression among HIV-infected women in Rural Uganda. PLoS One. 2012;7(12):e49821.

22. Okello ES, Abbo C, Muhwezi WW, Akello G, Ovuga E. Mental health literacy among secondary school students in North and Central Uganda: a qualitative study. World Cult Psychiatry Res Rev. 2014;9(3):70-80.

23. Kieling $\mathrm{C}$, Baker-Henningham $\mathrm{H}$, Belfer $\mathrm{M}$, et al. Child and adolescent mental health worldwide: evidence for action. Lancet. 2011;378(9801):1515-1525.

24. Kaddumukasa M, Mugenyi L, Kaddumukasa MN, et al. Prevalence and incidence of neurological disorders among adult Ugandans in Rural and Urban Mukono district; a cross-sectional study. BMC Neurol. 2016;16(1):227.
25. Mugyenyi P, Sewankambo N. Mentor's Manual for Health Sciences Training in Africa. Kampala: Fountain Publishers Limited; 2010.

26. University of Minnesota - Clinical and Translational Science Institute. Cryptococcal Optimal ART Timing Trial (COAT). Available from: https:/clinicaltrials.gov/ct2/show/NCT01075152. NLM identifier: NCT01075152. Accessed July 13, 2017.

27. Nakku D, Byaruhanga R, Bajunirwe F, Kyamwanga IT. A case control study of the factors associated with occurrence of aerodigestive foreign bodies in children in a regional referral hospital in South Western Uganda. BMC Ear Nose Throat Disord. 2016;16(1):5.

28. Ashaba S, Kaida A, Burns BF, et al. Understanding coping strategies during pregnancy and the postpartum period: a qualitative study of women living with HIV in Rural Uganda. BMC Pregnancy Childbirth. 2017;17(1) 138.

\section{Publish your work in this journal}

Advances in Medical Education and Practice is an international, peerreviewed, open access journal that aims to present and publish research on Medical Education covering medical, dental, nursing and allied health care professional education. The journal covers undergraduate education, postgraduate training and continuing medical education including emerging trends and innovative models linking education, research, and health care services. The manuscript management system is completely online and includes a very quick and fair peer-review system. Visit http://www.dovepress.com/testimonials.php to read real quotes from published authors.

Submit your manuscript here: http://www.dovepress.com/advances-in-medical-education-and-practice-journal 